Cadernos de História, Belo Horizonte, v. 22, n. 37, Novembro de 2021

DOI: https://doi.org/10.5752/P.2237-8871.2021v22n37p200-221

\title{
ENTRE O AMADORISMO E O PROFISSIONALISMO: A VÁRZEA \\ E AS TRANSFORMAÇÕES DO FUTEBOL NA CAPITAL MINEIRA NAS DÉCADAS DE 1940 E 1950
}

RAPHAEL RAJÃo RIBEIRO

Fundação Getúlio Vargas

raprajao@gmail.com

\section{RESUMO}

O presente artigo pretende abordar a conformação de um circuito competitivo do futebol de várzea, em Belo Horizonte, associado a processos que foram fundamentais para a estruturação do meio esportivo no Brasil. Ao utilizar como fonte os debates de um jornal com estreitas ligações com a vertente mais popular dessa modalidade atlética, são examinadas oposições e i nterseções durante o desenvolvimento da expressão amadorista da prática e a consolidação de sua versão espetacularizada. Passada mais de uma década da regulamentação do pagamento de salários aos jogadores, observavase a constituição de um mercado incipiente, incapaz de gerar rendas suficientes para a manutenção de um sistema de dedicação integral e exclusiva dos atletas. O cenário dos anos 1940 e 1950 na capital mineira ajuda a compreender como a definição dos circuitos de várzea e do futebol de espetáculo foi um processo longo, que teve na oficialização do profissionalismo, em 1933, apenas um de seus capítulos. Várias disputas seguiam em aberto naqueles tempos, quando as fronteiras entre os dois universos eram ainda muito indefinidas.

Palavras-chave: Futebol amador; profissionalismo; Belo Horizonte.

Recebido em 17 de setembro de 2020.

Aprovado em 11 de março de 2021. 
Cadernos de História, Belo Horizonte, v. 22, n. 37, Novembro de 2021

DOI: https://doi.org/10.5752/P.2237-8871.2021v22n37p200-221

\author{
BETWEEN AMATEURISM AND \\ PROFESSIONALISM: THE VÁRZEA \\ AND THE TRANSFORMATIONS OF \\ FOOTBALL IN THE CAPITAL OF MiNAS \\ GERAIS IN THE 1940S AND 1950 S \\ RAPHAEL RAJÃO RIBEIRO \\ Fundação Getúlio Vargas \\ raprajao@gmail.com
}

\begin{abstract}
This article aims to discuss the conformation of a competitive circuit of the amateur football in Belo Horizonte in relation to processes which were fundamentals to the structuring of sport business in Brazil. When using journal issues as source with close relations of the most popular line of these athletic practices, oppositions and intersections are examined during the development of the amateurism and the consolidations of it use as entertainment. More than a decade went by since the regulation of the payment of wages to the football players, may be observed the incipient increase in market, unable to generate proper income to maintain a system of fulltime and exclusive dedication to the athletes. The panorama in the capital in1940s and1950s propitiates understand how the definition of the várzea's circuit and football as entertainment was a long-term process, which had in the professionalism officialization, in 1933, just one of its chapters. Various competitions were pending in those days, when the boundary between the two universes was very tenuous.
\end{abstract}

Keywords: Amateur football; professionalism; Belo Horizonte. 


\title{
INTRODUÇÃo
}

No ano de 1956, o Diário da Tarde ${ }^{1}$ publicou entre os meses de maio e julho uma série intitulada "Radiografia do profissionalismo mineiro" na qual traçou um panorama da situação de nove dos dez clubes integrantes da divisão profissional da Federação Mineira de Futebol (FMF). As reportagens diagnosticavam a situação empregatícia dos atletas, com um balanço daqueles que reuniam ou não condições de se dedicarem exclusivamente à prática esportiva. Conforme informado no primeiro episódio dedicado ao Vila Nova, da cidade de Nova Lima:

\begin{abstract}
O regime remunerado em Minas apesar de ter sido adotado há vinte e três anos (desde 1933), continua incipiente, mal compreendido, quase falso. A rigor, dentre os nossos clubes profissionais, apenas dois (Atlético e América), agem de forma a serem considerados verdadeiramente profissionais, muito embora algumas poucas restrições. Os craques de Lourdes e da Alameda são integrados no regime com suas obrigações afetas somente ao clube que os contrataram, sendo mínima a percentagem daqueles que não fazem do futebol o seu meio de vida. Alvi-negros e alvi-verdes estão sempre dando exemplo de aquisições fora do Estado, buscando nomes que provoquem a curiosidade do público, com folhas de pagamentos vultosas, enfim, demonstrando adotarem, de fato, o regime que abraçaram.

Os demais, adotam ( $\mathrm{sic}$ ) um misto de profissionalismo e amadorismo marrom, representando este último critério na providencia de garantir para os seus "profissionais" empregos que variam entre o comércio, a indústria, o funcionalismo municipal, estadual e federal, colocações que venham possibilitar a permanência deste ou daquele valor. ${ }^{2}$
\end{abstract}

O argumento da matéria de abertura seria evidenciado a cada episódio com a demonstração de diferentes arranjos desenvolvidos pelos clubes para garantir o sustento de seus atletas. A existência de agremiações em cidades com instalações fabris permitia a manutenção de jogadores-operários, que se desdobravam entre a atividade industrial e a prática futebolística. Tal situação se verificava nos casos do Vila Nova de Nova Lima, associado à Companhia Morro Velho 3 , do Siderúrgica de Sabará, próximo à Companhia Siderúrgica Belgo Mineira ${ }^{4}$, do Asas de Lagoa Santa, baseado na fábrica de aviões existente ali ${ }^{5}$ e do Metalusina de Barão de Cocais, com relações com a usina metalúrgica local. ${ }^{6}$

Quanto às equipes belo-horizontinas do Cruzeiro e do Sete de Setembro, o que se observava era a manutenção de uma rede de apoio e de tráfico de influências, suportada pelos associados dos clubes, que permitia que atletas assumissem postos de trabalho no comércio local e em repartições públicas, com flexibilidade para se dedicarem aos treinamentos ${ }^{7}$. No caso do Sete de Setembro, a condição empregatícia de seu elenco levou a agremiação a transferir seus exercícios para o período noturno, de modo a não prejudicar o expediente regular dos

\footnotetext{
1 O Diário da Tarde era ligado aos Diários Associados, fundado por Assis Chateaubriand. Periódico vespertino, de perfil mais popular em relação ao coirmão Estado de Minas, o DT se dedicava, principalmente, à cobertura de temas esportivos, policiais e do cotidiano da capital mineira. Por vários anos, manteve colunas dedicadas a essa vertente específica do futebol, com destaque para aquela denominada Notas da Várzea.

2 RADIOGRAFIA DO PROFISSIONALISMO MINEIRO. Diário da Tarde, Belo Horizonte, p. 8, 25 de maio de 1956. 3 Cf. Ibidem.

4 Cf. RADIOGRAFIA DO PROFISSIONALISMO MINEIRO. Diário da Tarde, Belo Horizonte, p. 8, 30 de maio de 1956.

5 Cf. RADIOGRAFIA DO PROFISSIONALISMO MINEIRO. Diário da Tarde, Belo Horizonte, p. 8, 22 de junho de 1956.

6 Cf. RADIOGRAFIA DO PROFISSIONALISMO MINEIRO. Diário da Tarde, Belo Horizonte, p. 8, 28 de junho de 1956.

7 Cf. RADIOGRAFIA DO PROFISSIONALISMO MINEIRO. Diário da Tarde, Belo Horizonte, p. 8, 7 de junho de 1956; RADIOGRAFIA DO PROFISSIONALISMO MINEIRO. Diário da Tarde, Belo Horizonte, p. 8, 13 de junho de 1956.
} 
jogadores ${ }^{8}$. O novato Democrata, de Sete Lagoas, que até tinha seis profissionais integrais, dependia de uma "caixinha" sustentada por alguns de seus diretores. 9

Nessa perspectiva, somente duas agremiações da divisão profissional da FMF tinham a maioria de seus atletas com dedicação exclusiva à preparação e às partidas: Atlético e América, ambas da capital mineira. Apenas essas custeavam seus elencos diretamente, em boa parte com rendas geradas por suas próprias atividades.

O quadro traçado pelas reportagens do Diário da Tarde indica um profissionalismo que não era autossustentável. Passadas mais de duas décadas da formalização da remuneração de atletas no futebol belo-horizontino, equipes tradicionais, com estádios próprios, como Cruzeiro e Sete de Setembro, dependiam de arranjos similares aos anteriores a $1933^{10}$. Tal situação não era exclusiva do meio esportivo mineiro, como revela, por exemplo, o relato de Rui Campos, meia do São Paulo e da Seleção Brasileira nos anos 1940 e 1950, prestado ao Museu da Imagem e do Som de São Paulo, dentro do projeto "Memórias do Futebol", que comenta a conciliação, durante toda sua carreira, entre cargos no governo do Estado de São Paulo e a condição de atleta.

A identificação de um meio profissional em busca de consolidação na metade dos anos 1950 chama a atenção para o fato de que o processo de constituição do futebol como espetáculo rentável e autossustentável prolonga-se por várias décadas. Apesar da importância do reconhecimento do regime de remuneração de atletas a partir de 1933, o qual não se efetivou simultaneamente em todas as regiões brasileiras, tal marco faz parte de um fenômeno de duração mais longa que não se encerra nele, como bem destaca Arlei Damo:

\footnotetext{
O primeiro dá conta de que o ano de 1933, embora sirva como referência, não pode levar a crer que o acordo entre as agremiações paulistas e cariocas tenha modificado radicalmente $o$ que quer que seja, muito menos que tenha reverberado de modo idêntico em todas as partes do Brasil. A profissionalização dos pés-de-obra é paralela ao processo de espetacularização do futebol e este é matizado, entre outros fatores, pela urbanização, pelo desenvolvimento dos meios de transporte e de comunicação, incluindo-se a invenção do jornalismo especializado. Por tais motivos, a espetacularização do futebol no Brasil é um processo inacabado e diversificado, embora tenha se consolidado um circuito nacional, a partir dos anos de 1970, do qual faz parte a elite clubística. (DAMO, 2005, p. 171)
}

Nesse sentido, é possível pensar o reconhecimento da profissionalização dos atletas como parte do fenômeno mais abrangente de criação de um circuito do futebol de espetáculo em diferentes cidades brasileiras. A possibilidade da cobrança de entradas e da geração de um mercado de consumo voltado para o fomento de disputas futebolísticas remonta ao início do século XX, momento ainda embrionário da modalidade no Brasil (Cf. GAMBETA, 2013; SANTOS, 2010). A constituição de uma elite de clubes que capitaneou esse processo, especialmente, por meio das entidades dirigentes e que concentrou o poder de definir as condições para o ingresso no circuito que se consolidava pôde ser observada desde a fase

8 Cf. O SETE NÃO PODE AMARRAR-SE MAIS À MENTALIDADE AMADORISTA. Diário da Tarde, Belo Horizonte, p. 6, 20 caderno, 17 de julho de 1958.

9 Cf. RADIOGRAFIA DO PROFISSIONALISMO MINEIRO. Diário da Tarde, Belo Horizonte, p. 8, 28 de junho de 1956.

10 Há vasta bibliografia que documenta a prática de remuneração de atletas de futebol antes de 1933, em cidades das diferentes regiões brasileiras, em um arranjo conhecido como amadorismo marrom, que envolvia variadas táticas para garantir benefícios financeiros a jogadores que oficialmente eram apresentados como não profissionais. Para um panorama desse cenário ver: GOMES; PINHEIRO, 2015. 
inaugural dessa prática atlética.

Dessa forma, a distinção de uma série de agremiações ou de tipos de agremiações que estariam apartadas de um circuito que se estabelecia remonta à própria estruturação do campo esportivo nas diferentes cidades. A oposição entre clubes profissionais e amadores que consagraria tal separação não seria instituinte dessa segregação, mas sim um desdobramento do fenômeno de bases anteriores. Essa separação, como será demonstrada neste texto, em diversos momentos vivenciou situações tênues, a exemplo da condição semiprofissional que as equipes da principal divisão da Federação Mineira de Futebol (FMF) experimentavam na década de 1950.

A opção pela categoria circuito para distinguir, de um lado, o amplo universo de práticas desenvolvidas por equipes integrantes de um meio esportivo formal e informal aderente ao futebol amador, e de outro, aquele associado à versão espetacularizada do jogo, baseada na comercialização de ingressos e em outras formas de mercantilização, se dá, em especial, a partir do diálogo com dois autores, Mauro Myskiw e Arlei Damo.

Em sua tese, Mauro Myskiw desenvolveu estudo etnográfico com times de Porto Alegre entre os anos de 2009 e 2011. Durante seu esforço de delimitação do objeto de pesquisa, o autor rapidamente percebeu a diversidade de situações em que o termo várzea era utilizado, às vezes representando um lugar - na várzea -, às vezes algo, uma coisa - a várzea (Cf. MYSKIW, 2012, p. 28). Para auxiliar seu esforço de análise, o pesquisador recorreu à categoria circuito, proposta pelo antropólogo José Guilherme Magnani, que se refere a um conjunto “(...) que une estabelecimentos, espaços e equipamentos caracterizados pelo exercício de determinada prática ou oferta de determinado serviço, porém não contíguos na paisagem urbana, sendo reconhecidos em sua totalidade apenas pelos usuários (...)” (MAGNANI, 2008, p. 45). A partir dessa demarcação, Myskiw conseguia circunscrever um grupo de práticas e espaços que se diferenciavam de outras expressões futebolísticas vivenciadas em Porto Alegre.

Ao considerar a diversidade de expressões que essa modalidade esportiva experimentou e experimenta, Arlei Damo cunhou em sua tese a categoria futebóis, com a identificação do que chamou de diferentes matrizes futebolísticas: espetacularizada, comunitária, bricolada e escolar (DAMO, 2005, p. 36-44). Mais recentemente, ao revisitar o debate, o autor comentou sobre a melhor adequação da noção de circuito, ainda que a partir de uma referência diversa da utilizada por Mauro Myskiw:

\footnotetext{
A noção de matriz deu mais a ideia de um sistema do que de processo ou de fluxo. Tivesse a oportunidade de reescrever a proposta, provavelmente substituiria "matriz" por "circuito", inspirado na utilização deste termo por Viviana Zelizer (2005) ao tratar da diversidade de mercados no espectro do capitalismo, porque o termo sugere uma ideia de fluxo - no caso da formação de jogadores poderia ser pensado como um fluxo de praticantes, de técnicas corporais, de modos de governo, de dinheiro, afetos e assim por diante. A noção de Zelizer ajudaria a pensar que as práticas atinentes à formação e atuação profissionais fazem parte de um circuito específico, uma espécie de mainstream, vistas como legítimas do ponto de vista da estética e da eficácia. (DAMO, 2018, p. 49)
}

Em ambas as referências, os enquadramentos buscam lidar com a diversidade das expressões futebolísticas por meio de noções de descontinuidade e fluidez. Da mesma maneira, pressupõe-se um reconhecimento social que permite que comunidades internas e externas a essas práticas as percebam como conjunto, um universo, que, neste caso, seria denominado 
de a várzea ${ }^{11}$, mesmo que não goze de uma estrutura fixa e contínua.

A construção dessa ideia ou desse espaço simbólico que viria a ser identificado em $\mathrm{BH}$ como a várzea local possui uma historicidade que abarca múltiplos eventos que resultaram na configuração que tal circuito assumiu na capital mineira. Foi em diálogo com as reconfigurações do meio esportivo nacional e regional, com a dinâmica do mercado e do mundo do trabalho, com as transformações da cidade, com as expressões culturais populares e com as estratégias de controle e de luta política que essa expressão futebolística foi se moldando e reinventando na experiência cotidiana dos seus adeptos.

Para se passar ao exame dos embates que cercavam a constituição de um circuito da várzea no final da década de 1940, período abordado por este texto, faz-se necessária uma pequena digressão sobre os antecedentes da disputa institucional em torno da condução do futebol amador na capital mineira.

\section{A OFICIALIZAÇÃo DO FUTEBol AMADOR}

Como apontado antes, a formação de uma elite de clubes que lideraram a formação de um circuito do futebol de espetáculo, os quais assumiram o controle sobre as entidades diretivas e impuseram limites à participação das demais agremiações em suas competições, refere-se ao período inaugural da modalidade em diversas cidades brasileiras. São inúmeras referências às separações de equipes com a fundação de ligas alternativas para driblar as vedações impostas pelos grupos hegemônicos nos meios esportivos ${ }^{12}$. Nessa medida, a segregação de agremiações originadas da associação de trabalhadores braçais, de negros, de pobres e de moradores de áreas suburbanas foi observada desde as primeiras décadas da prática no país.

No caso de BH, observou-se a organização de clubes de futebol em bairros populares poucos anos após a criação das agremiações mais tradicionais. Em 1910, - ou seja, apenas dois anos depois da fundação do Atlético, a primeira associação a se consolidar na cidade surgiu no bairro operário do Barro Preto, o Yale Athletic Club (RIBEIRO, 2018, p. 70). Em 1913, registrava-se a existência de equipes em bairros suburbanos como Floresta e Lagoinha (RIBEIRO, 2018, p. 79). Ainda segundo Ribeiro (2018), com um número limitado de times na cidade, alguns mais bem estruturados como o Yale participaram das primeiras edições da competição da Liga Mineira de Sports Athleticos (LMSA), o que perdurou até o início dos anos 1920.

A médio prazo, a tendência foi a de acomodação das equipes suburbanas na principiante segunda divisão da Liga Mineira de Desportes Terrestres (LMDT). No campeonato de 1928, por exemplo, além de Atlético, América, Cruzeiro - então, Palestra Itália - e Sete de Setembro, apenas outros dois clubes belo-horizontinos, ambos do bairro da Lagoinha, Fluminense e Guarani, integravam a primeira divisão ao lado do Vila Nova, de Nova Lima e do Alves Nogueira, de Sabará. As demais associações da capital mineira concentravam-se na divisão inferior ${ }^{13}$.

11 Outra referência digna de nota à utilização da noção de circuito da várzea encontra-se na obra de Gilmar Mascarenhas, que estabelece a comparação entre um circuito corporativo (fabril e comercial) e um do futebol de várzea, para abordar caminhos da popularização da modalidade nas cidades brasileiras. Cf. MASCARENHAS, 2014 , p. 98.

12 (Cf. GAMBETA, 2013; PEREIRA, 2000; SANTOS JUNIOR, 2014; SOUZA, 2018; SOUZA; CAPRARO, 2015, p. 235-263)

13 Cf. ASSIS, Anatólio Alves de. Recordações de BH do passado, do "footing” ao "football”. Diário da Tarde. Belo Horizonte, 23 de julho de 1981, p. 9. 
Estrutura semelhante era observada no início da década de 1930 (MAYOR, 2017, p. 166).

Conforme Lage e Medeiros (2014), a distinção representada na organização da liga local se expressaria na passagem ao profissionalismo. Inicialmente, apenas Atlético, América e Palestra Itália aderiram à regulamentação da remuneração de atletas dentre os clubes belohorizontinos em 1933. O Sete de Setembro se articulou com outras entidades para a criação de uma liga amadora, mas terminaria por ingressar no novo regime no ano seguinte (MAYOR, 2017, p. 214-216). Assim, as demais equipes da capital mineira passaram a se mobilizar para organizar disputas entre as que seguiram no amadorismo.

Os anos que se seguiram foram de tentativas de criação de entidades dirigentes capazes de agregar os clubes que se mantiveram ligados à expressão amadora da prática futebolística, como rememorou uma matéria do Diário da Tarde:

\begin{abstract}
(...) Surgiu, então sob os auspícios do DIÁRIO DA TARDE, numa iniciativa brilhante de Menotti Mucelli, cuja memória reverenciamos, a primeira liga de amadores da capital L.A.F. (Liga Amadorista de Futebol. (sic) (...) Posteriormente, apareceu o D.A. (Departamento Amadorista), entidade prestigiada pela então Liga de Futebol de Belo Horizonte ou Liga Mineira de Desportos Terrestres, que se transformou, posteriormente, na Federação Mineira de Futebol. ${ }^{14}$
\end{abstract}

Uma narrativa parecida é apresentada na tese de Sarah Soutto Mayor, que igualmente aponta para o movimento de criação de uma entidade responsável pelas disputas amadoristas atrelada à estrutura institucional responsável pela organização das agremiações profissionais, no caso, a Liga de Futebol de Belo Horizonte (LFBH) (MAYOR, 2017, p. 217). Essa tendência de subordinação seria consolidada na década seguinte, mais especificamente em 1942, como parte de um fenômeno maior de remodelação esportiva nacional.

O início da década de 1940 foi um momento central para a estruturação da política esportiva nacional, a qual se expressou, principalmente, na edição do Decreto-Lei 3.199 de 14 de abril de 1941. Tal legislação, além de criar o Conselho Nacional de Desportos (CND), ao qual se subordinava toda a rede de entidades diretivas do setor, estabeleceu outras orientações para o desenvolvimento das modalidades atléticas no país, reproduzindo a mesma lógica de unicidade que se via no controle das associações sindicais ${ }^{15}$.

Sob o novo regime, cabia ao CND a regulamentação da organização e das práticas esportivas no país, o que ocorria por meio de uma série de normativas do órgão, que tinha por objetivo complementar as diretrizes gerais apresentadas no Decreto-Lei 3.199/41 (BRASIL, 1941). Foi sob essa prerrogativa que o conselho estabeleceu em outubro de 1942 que: "Numero 13 - Cada Federação manterá um Departamento de Futebol Amador, com Organização própria, dirigido por um delegado por escolha do presidente (...)" ${ }^{\prime 16}$. Seguindo a imposição do órgão superior federal, em 16 de dezembro de 1942, foi instalado o Departamento de Futebol Amador (DFA) ${ }^{17}$ como parte da estrutura da Federação Mineira de Futebol (FMF), entidade criada em 1939 (MAYOR, 2017, p. 217).

No intuito de se recuperar os antecedentes da constituição de uma estrutura oficial

14 Um pouco da história do futebol amador de Belo Horizonte. Diário da Tarde. Belo Horizonte, 16 de maio de 1956, p. 8.

15 Cf. LINHALES, 1996; SOARES, 2015; SOUZA, 2008.

16 “DEIXEM CÔRTES TRABALHAR”. Diário da Tarde. Belo Horizonte, 18 de julho de 1956, p. 8.

17 DFA - LEGENDA DO AMADORISMO DE BELO HORIZONTE. Diário da Tarde. Belo Horizonte, p. 9, $3^{\circ}$

caderno, 12 de dezembro de 1956. 
do futebol amador da capital mineira, deve-se, por fim, pontuar a criação de um órgão disciplinar a partir da configuração da Justiça Desportiva, pelo CND, em 1945. Em seu arranjo institucional, duas instâncias atuavam em âmbito estadual, o Tribunal de Justiça Desportiva (TJD) e a Junta Disciplinar Desportiva (JDD), esta dedicada à expressão amadora do esporte (SOARES, 2015, p. 285-286).

É, portanto, a partir desse cenário, com a estruturação de uma organização oficial da várzea local por meio do Departamento de Futebol Amador (DFA) e de uma instância disciplinar, a Junta Disciplinar Desportiva (JDD), que constatou-se os embates em torno da constituição de um circuito que articulasse as equipes de futebol amador em $\mathrm{BH}$. Nesse contexto, variados interesses estavam em disputa. No presente artigo, esse processo será examinado sob a perspectiva das oposições entre um futebol de espetáculo, ainda em desenvolvimento, com dificuldades de estabelecer um regime autossustentável que garantisse o pagamento de atletas para a dedicação integral ao esporte e um meio varzeano que transgredia os limites do regime amadorista em que havia sido lançado.

\section{ENTRE O AMADORISMO E O PROFISSIONALISMO}

Em 1948, o profissionalismo coordenado pela FMF tinha alcance limitado, o campeonato local contava apenas com sete equipes, quatro delas da capital, além do Siderúrgica de Sabará, do Metalusina de Barão de Cocais e do Vila Nova de Nova Lima, todas cidades situadas a um raio de 100 quilômetros de Belo Horizonte. No ano anterior, a entidade diretiva mineira organizou o que chamou de I Campeonato Estadual de Futebol, desdobramento da realização do I Campeonato do Interior, promovendo um certame entre agremiações das diferentes ligas municipais e regionais. Como forma de incremento da modalidade em Minas Gerais, a presidência da federação propunha a criação, a partir de 1949, da $2^{\text {a }}$ divisão profissional, para o que esperava arregimentar "clubes da Capital, de eficiência técnica comprovada e, possivelmente, associações das cidades vizinhas" ${ }^{18}$.

Como citado anteriormente, desde ao menos o início da década de 1920, as disputas do então campeonato da cidade envolviam a participação de clubes da capital mineira e de localidades vizinhas, como Nova Lima e Sabará. A adesão de agremiações às ligas que hegemonizaram o futebol de espetáculo em Belo Horizonte até a regulamentação do profissionalismo envolvia a presença de cerca de duas dezenas de equipes, separadas em duas divisões. Com o advento do regime oficial de remuneração de atletas, considerável parcela das associações abdicou da disputa do principal torneio local, que em sua nova versão, contou entre os belo-horizontinos apenas com América, Atlético e Palestra Itália, com a adesão do Sete de Setembro, a partir de 1934 (MAYOR, 2017, p. 216).

Nessa medida, diversas agremiações que, embora não gozassem de protagonismo na principal liga belo-horizontina compunham o mais prestigiado torneio local, a partir do advento do profissionalismo, passaram a atuar num circuito diverso, associado à várzea, onde outros tantos times já desenvolviam pequenos certames e se organizavam de maneira autônoma. Com boa estrutura material, mantendo campos e sedes próprias e com um corpo de sócios contribuintes razoável, tais clubes viviam o impasse de arcar com os custos do regime oficializado de remuneração de atletas ou de seguirem no amadorismo, talvez sem a mesma

18 EM 49, A CRIAÇÃO DA II DIVISÃO DA F.M.F. Diário da Tarde. p. 4 e 5, 20 de dezembro de 1948. 
visibilidade garantida pelo esporte de espetáculo. Por outro lado, com um número restrito de participantes, o campeonato mantido pela Federação Mineira de Futebol mostrava-se incapaz de ocupar parcela considerável do calendário de seus participantes, demandando a ampliação do quantitativo de concorrentes.

Liderada por um político com estreitas relações com o futebol, o prefeito Otacílio Negrão de Lima, ex-atleta e dirigente do América, a municipalidade procurava intervir com o objetivo de incrementar o espetáculo esportivo local, para o que organizou um plano de apoio à profissionalização de equipes da capital mineira, que consistia no seguinte:

\begin{abstract}
Faz três meses que o futebol amador viveu um período de intensa expectativa, com as demarches para a escolha de dois clubes inscritos no Departamento de Futebol Amador a fim de preencherem o quadro da primeira categoria da Federação Mineira de Futebol.

Depois de prolongadas conversações de exames das documentações apresentadas pelos clubes, depois de uma serie infindável de exigências que deveriam ser satisfeitas pelos grêmios amadoristas, os membros da comissão encolhida ( $s i c$ ), em reuniões sucessivas, ponderando todos os requisitos oferecidos pelos candidatos á ascensão, optaram pela elevação do Tremedal e do Terrestre á categoria profissional.

Vencida, portanto, a primeira fase das providencias que se prendiam ao estudo e apreciação das condições que poderiam oferecer os clubes para a sua promoção ao profissionalismo, estava a segunda parte, qual seja a da construção das praças de esportes para os que fossem elevados. O trabalho da comissão presidida pelo saudoso vereador Alvaro Celso de Trindade, se desenvolveu dentro do mais rigoroso critério, sendo atendidos todos os requisitos exigidos ao fim das continuadas reuniões, pode a comissão chegar, com a brevidade esperada, á colimação do fim a que estava sendo pretendido. (DIÁRIO DA TARDE, 1948, p. 5).
\end{abstract}

Com vistas a atender a necessidade de ampliação das equipes na divisão da FMF, a Prefeitura de Belo Horizonte (PBH) encampou a missão de financiar a profissionalização de duas equipes vinculadas ao DFA. Como relata o trecho, foram selecionados o Terrestre, do bairro da Lagoinha ${ }^{19}$, e o Tremedal, do Carlos Prates ${ }^{20}$. Ambas as agremiações, para além da boa estrutura, tinham destacada atuação na política esportiva local. Uma reportagem do Diário da Tarde (1956) recordava que, até aquele ano, apenas dois diretores do DFA não tinham saído das fileiras do Tremedal (DIÁRIO DA TARDE, 1956, p. 8 e 9).

Para além do peso político envolvido na escolha, é interessante perceber como o plano de profissionalização passava pela necessária construção de uma praça de esportes para cada uma das entidades, com financiamento municipal. Conforme Santos (2010), nesse momento, boa parte da sustentabilidade do futebol de espetáculo baseava-se na cobrança de ingressos para as disputas esportivas. Portanto, era fundamental a existência de um estádio próprio para garantir a transição das agremiações amadoras ao novo regime.

Em um contexto de profissionalismo em processo, a estrutura de um clube varzeano de elite pouco se diferenciava da de uma agremiação da liga principal de segundo escalão. $\mathrm{O}$

19 A Lagoinha é um dos bairros de ocupação mais precoce na nova capital mineira. Integrante da Sexta Seção Suburbana, na divisão proposta pelo plano original, acolheu boa parte dos operários e trabalhadores braçais, nacionais e estrangeiros, que atuaram nos primeiros anos de Belo Horizonte. Também ficou marcada como área comercial e boêmia da cidade, especialmente até os anos 1960. Foi berço de importantes clubes, como Guarani, Fluminense, Pitangui, Lagoinha e o próprio Terrestre. Cf. ARREGUY; RIBEIRO. Regional Noroeste, 2008.

20 Originado da subdivisão de terrenos da Colônia Agrícola Carlos Prates e com população operária, o bairro formado às margens do Córrego do Pastinho, aos poucos ganhava ares de classe média, impulsionado pela canalização do curso d'água e pela abertura da Avenida Pedro II. Cf. ARREGUY; RIBEIRO. Regional Noroeste, 2008. 
Tremedal, que, em 1956, vangloriava-se de ser a mais organizada entidade do amadorismo, ostentava "(...) séde (cedida pelo Govêrno do Estado), onde faz funcionar, com brilho, uma Escola Infantil. Está construindo vestiários e quadras para volei e basquetebol”21.

Apesar do anúncio da PBH sobre a incorporação de dois clubes da capital na liga principal da FMF, o que gerou o pedido de desligamento de Terrestre e Tremedal dos quadros do $\mathrm{DFA}^{22}$, a entidade diretiva estadual parecia ter um plano diverso, com a divulgação da criação de sua $2^{\text {a }}$ divisão profissional que, além das duas agremiações citadas, comportaria os belo-horizontinos Fluminense, Santa Teresa e Pampulha, e os interioranos Pedro Leopoldo e União Itabirito ${ }^{23}$. O "rebaixamento" das duas equipes selecionadas pela municipalidade deu início a um impasse, uma vez que elas não mais teriam a possibilidade de se envolver em competição com os principais times locais, o que frustrava consideravelmente a visibilidade, o prestígio e as previsões de arrecadação com venda de ingressos que esperavam. Frente a isso, o presidente do Tremedal rejeitava a proposta de integrar uma divisão inferior ${ }^{24}$.

A persistência da querela, incluindo o recuo da $\mathrm{PBH}$ em relação ao financiamento da construção dos estádios ${ }^{25}$, fez com que a ideia de uma $2^{\text {a }}$ divisão profissional esfriasse e que a sua implantação para o ano de 1949 não vingasse. Em 1950, o debate seria retomado, com a indicação do sucesso alcançado pelo campeonato de acesso no estado de São Paulo. Contudo, a resistência de muitas equipes do interior mineiro de aderirem ao regime profissional era apresentada como motivação principal da dificuldade de implantar tal iniciativa ${ }^{26}$.

O tema da incorporação de equipes do circuito varzeano nas competições masculinas adultas da FMF, seja com a ampliação de vagas na divisão de elite, seja com a criação de uma $2^{\text {a }}$ divisão persistiria nos anos 1950. Em 1952, o DFA anunciava que escolheria duas agremiações as quais teriam apoio para a profissionalização ${ }^{27}$, proposta que não teve maiores desdobramentos. Da mesma maneira, a questão da $2^{\text {a }}$ divisão era retomada, com nova indicação de um fracasso ${ }^{28}$. Não havia demonstrações de força daquele regime para permitir sua expansão.

Um dos principais desafios enfrentados pelos clubes da divisão principal da FMF era garantir uma sequência de partidas com bons públicos que permitissem arrecadação suficiente para arcar com os custos inerentes ao profissionalismo e ampliar seus elencos, oferecendo espetáculos ainda mais atraentes. Essa preocupação mobilizava as agremiações que, em 1950, formularam uma proposta para contornar a crise que se impunha:

O desinteresse do publico pelos jogos do atual certame tornou-se evidente. Aos poucos, os apaixonados vão fugindo dos estádios, observando-se esta verdade através da reduzida

21 A INFLUENCIA DO TREMEDAL NO AMADORISMO DE B. HORIZONTE. Diário da Tarde. Belo Horizonte, p. 8 e 9,5 de janeiro de 1956.

22 TREMEDAL E TERRESTRE DESISTIRAM DO CAMPEONATO DO DEPARTAMENTO DE FUTEBOL

AMADOR. Diário da Tarde, 5 de outubro de 1948, , p. 4, Belo Horizonte.

23 SERÁ CRIADA A SEGUNDA DIVISÃO DE PROFISSIONAIS. Diário da Tarde. Belo Horizonte, 2 de dezembro de 1948 , p. 5.

24 Cf. EXPLICA O SR. HELIO MOSCI. Diário da Tarde. Belo Horizonte, 21 de dezembro de 1948, p. 5.

25 Cf. TERRESTRE E TREMEDAL NA “BERLINDA”. Diário da Tarde. Belo Horizonte 19 de janeiro de 1949 , p. 5.

26 Cf. A CRIAÇÃO DA 2a DIVISÃO DE PROFISSIONAIS. Diário da Tarde. Belo Horizonte., 23 de maio de 1950, p. 4.

27 Cf. Dois clubes amadoristas para a divisão de profissionais. Diário da Tarde. Belo Horizonte, 29 de março de 1951, p. 5.

28 Cf. CONDENADA AO FRACASSO A 2a DIVISÃO DE PROFISSIONAIS. Diário da Tarde. Belo Horizonte, 31 de março de 1952, p. 8 . 
receita até agora apresentada quando cerca de dez rodadas já foram levadas a efeito. Sentiu-se a necessidade urgente de se tomar providencias para o retorno de grandes públicos aos espetáculos futebolísticos, a fim de impedir a derrocada do "association" montanhês. E foi por isso que, por iniciativa dos próprios clubes, se reuniu ontem á noite o Conselho Divisional da Federação Mineira de Futebol, na sede daquela entidade. (...)

Aproveitando a presença do sr. Constantino Siqueira, representante dos clubes amadoristas junto á FMF entenderam-se os membros do Conselho Divisional com o objetivo de que se possa organizar entre os mais expressivos grêmios amadoristas, um certame extra, o qual seria disputado nas preliminares dos jogos profissionais.

As partidas entre os aspirantes passariam a ser realizadas aos sábados, de acordo com o que se projetou. (...)

Segundo estamos informados, os clubes entre os quais seriam escolhidos os que participariam do campeonato extra são os seguintes:

Santa Teresa, Fluminense, Tremedal, Parque Riachuelo, Terrestre, Ferroviário, Vila Concordia, Inconfidência, Indústrias Reunidas e Horizonte Têxtil.

Trata-se de agremiações que indiscutivelmente desfrutam de grande popularidade no cenário do futebol amador da cidade. (...)

Espera-se que os clubes saibam corresponder á iniciativa, que lhes proporcionará inúmeras vantagens. Teriam eles, alem de fornecimento gratuito de bola pela FMF, juízes sem qualquer ônus.

Receberiam, ainda, uma quota de 50 centavos em cada ingresso do espetáculo de que tomassem parte (DIÁRIO DA TARDE, 1950, p. 5).

Ao aproveitar-se da popularidade dos varzeanos, os clubes profissionais queriam ampliar seus públicos e, ao mesmo tempo, eliminar disputas concorrentes que direcionavam parte dos torcedores para as beiras dos campos de terra espalhados pela cidade. Como avaliava o Diário da Tarde (1950):

Entre as inúmeras causas da quebra de renda nos espetáculos futebolísticos em Belo Horizonte, a programação dos jogos do certame amadorista no mesmo horário em que se realizam os jogos do certame profissional, sempre foi encarada como das mais danosas (DIÁRIO DA TARDE, 1950, p. 4).

Em troca de alguns benefícios, os integrantes da principal divisão da FMF buscavam incorporar tradicionais equipes do circuito amadorista. Em reunião no final de setembro de 1950, as entidades filiadas ao DFA apreciaram a proposta dos profissionais que era ligeiramente diferente da citada acima, uma vez que a quota de 50 centavos incidiria tão somente sobre as entradas das gerais e não sobre todos os ingressos, como noticiado no início daquele mês. Após avaliação e discussão, as agremiações varzeanas optaram pela rejeição e argumentaram que:

vêm sofrendo [prejuízos] com essa questão das rendas, pois é sabido que, tempos atrás, percebiam a importância de 10 centavos por ingresso vendido nos estádios de Belo Horizonte, ajuda essa que foi posteriormente cortada (DIÁRIO DA TARDE, 1950, p. 11).

À recusa dos integrantes do DFA, seguiram-se ameaças de represálias dos clubes profissionais, segundo noticiado pelo Diário da Tarde:

A medida tomada pelos clubes amadoristas deverá sofrer represálias por parte dos clubes profissionais. Acham estes que os pequenos clubes não querem cooperar no soerguimento do futebol amador, campanha a pouco iniciada e que visa levantar o nível técnico e financeiro do nosso futebol (...) 
Não se justifica a atitude dos pequenos clubes, mormente em se sabendo que a campanha não visa a interesses secundários, mas tão somente à melhoria do futebol mineiro.

Diante disso, os clubes profissionais não mais cederão os seus estádios para partidas ou festivais amadoristas, bem como não lhes farão outras concessões, conforme apuramos nos altos círculos da F.M.F. (DIÁRIO DA TARDE, 1950, p. 11).

O episódio do torneio extra de equipes amadoras é revelador das contradições enfrentadas pelos dois circuitos em BH, em inícios dos anos 1950. Enquanto as equipes profissionais se esforçavam para encontrar uma forma rentável e sustentável para o espetáculo esportivo na capital mineira, as agremiações varzeanas buscavam garantir benefícios de sua subordinação a um regime oficial, capitaneado pelo DFA, mas articulado a uma vasta estrutura burocrática, que permitisse o acesso a recursos variados que suportassem suas atividades cotidianas. Em um contexto de baixa capacidade de produção de disputas absorventes pelos clubes da primeira divisão da FMF, até mesmo um circuito de várzea que gozava de pouco prestígio e visibilidade entre os veículos de comunicação locais poderia representar uma ameaça, dada a sua popularidade e o acesso franqueado aos inúmeros jogos que se desenrolavam nos finais de semana.

A falta de controle de entrada de público nas partidas varzeanas não permite dimensionar o contingente mobilizado nos jogos ${ }^{29}$, mas a preocupação das equipes profissionais com a concorrência de jogos amadores era um tema de relativa recorrência. Em 1963, por exemplo, a tentativa de abarcar esses torcedores teria feito com que as partidas principais do Campeonato de Belo Horizonte, torneio extra proposto pelo América para preencher o calendário dos clubes, tivessem seus dias alterados, como informado a seguir:

A exemplo do que ocorre em São Paulo, por ocasião do certame paulista, os clássicos seriam efetuados às quintas-feiras, a fim de proporcionar aos adeptos do futebol varzeano, cujos espetáculos são realizados aos domingos, a oportunidade de assistir às partidas mais importantes do "Campeonato de Belo Horizonte" ${ }^{30}$.

A não cobrança de ingressos nas disputas amadoristas ocorria, inclusive, por questões materiais, já que boa parte dos campos utilizados não dispunha de fechamento que pudesse garantir o controle de público e a instalação de uma bilheteria. Contudo, em algumas ocasiões, houve tentativas, por parte das equipes e do DFA, de realizar a venda de entradas para jogos do circuito vazeano. Eram momentos em que um dos principais elementos distintivos em relação a um circuito do futebol de espetáculo era tensionado.

A comercialização de ingressos para partidas amadoras pressupunha a sua transferência para algum dos estádios da capital mineira, a maioria deles ligada às entidades profissionais, mas também exigia uma excepcionalidade da contenda, que deveria ser um jogo da fase mais aguda do campeonato do $\mathrm{DFA}^{31}$, um clássico entre equipes populares no circuito $^{32}$ ou uma partida interestadual ${ }^{33}$. A baixa ocorrência de pelejas com ingressos pagos indica que essa era

29 Em 1963, o Diário da Tarde estimou uma média de 3 mil torcedores por jogo durante rodada do campeonato do DFA, o que ao todo significaria mais de 20 mil espectadores. Cf. ROSARIO E S. FRANCISCO VENCERAM OS LIDERES NO SETOR VARZEANO. Diário da Tarde, 25 de novembro de 1963, p. 4, $2^{\circ}$ caderno, Belo Horizonte. 30 "Campeonato de Belo Horizonte" pode evitar a inatividade de 7 clubs. Diário da Tarde, 24 de dezembro de 1963, p. 8. $2^{\circ}$ caderno, Belo Horizonte.

31 Cf. Encerramento do Super-Campeonato. Diário da Tarde, 6 de abril de 1950, p. 5, Belo Horizonte.

32 Cf. A nova programação do festival amadorista. Diário da Tarde, 13 de maio de 1950, p. 5 e 7, Belo Horizonte.

33 Cf. MINEIROS COMEÇAM GANHANDO: 2 X 1. Diário da Tarde, 9 de dezembro de 1958, p. 5. $2^{\circ}$ caderno, Belo Horizonte. 
mais uma oportunidade de rendas esporádicas do que uma estratégia de sustentabilidade para os clubes.

Dessa forma, a realização de partidas que, em regra, eram de entrada franca em campos abertos ao público representa uma diferença importante entre um circuito de várzea e um circuito do futebol de espetáculo. Clubes amadores tinham suas rendas menos baseadas na mercantilização dos jogos e mais ligadas ao fomento por grupos de apoiadores ou ao acesso a verbas públicas. Tais variações são mais relevantes como marcas distintivas desse conjunto de agremiações do que a remuneração de seus atletas que, como será demonstrado a seguir, era tendência presente nas duas expressões dessa modalidade esportiva em BH.

A ideia da "várzea como celeiro de craques" era especialmente forte nos anos 1940 e 1950. Não eram raros os casos de transições de atletas que no mês anterior estavam em disputas do circuito amadorista e, de repente, ingressavam nas fileiras das equipes da divisão profissional da FMF. Reportagens sobre jogadores que despontaram em pequenas agremiações da cidade e que vieram a alcançar fama em clubes do futebol de espetáculo eram recorrentes ${ }^{34}$. A pouca força do meio esportivo local era representada, inclusive, pela perda de talentos varzeanos para concorrentes cariocas ${ }^{35}$.

A possibilidade de se garimpar craques no circuito amadorista vislumbrada pelas agremiações profissionais e a atuação de membros da imprensa na organização esportiva belo-horizontina proporcionou um interessante caso no final dos anos 1949: a criação de uma equipe de várzea do Clube Atlético Mineiro. A proposta partiu do técnico Chico Trindade, que já teria experimento, com sucesso, a fórmula no Cruzeiro, quando revelou sete bons jogadores para o elenco profissional ${ }^{36}$. $\mathrm{Na}$ nova empreitada, foi escalado o veterano cronista Mario Batista, o "Matista", para organizar o time que disputaria os campeonatos do DFA ${ }^{37}$. A estreia atleticana aconteceu em um festival orgvanizado por seu diretor esportivo, evento que previu a cobrança de ingressos ${ }^{38}$. Novos exercícios foram realizados pela equipe varzeana do Atlético, retratada numa dessas ocasiões.

34 Cf. ANO AUREO DO AMADORISMO. Diário da Tarde. Belo Horizonte,14 de dezembro de 1948, p. 5.. Os grandes clubes pouca chance oferecem ao "cracks" varzeanos. Diário da Tarde. Belo Horizonte 31 de janeiro de 1949, p. 6; Cf. Flôr de Minas, uma forja de "cracks". Diário da Tarde. Belo Horizonte, 6 de março de 1952, p. 6; Atletas amadores se transferem para o profissionalismo. Diário da Tarde. Belo Horizonte 4 de setembro de 1952, p. 5; Cf. COM ARMAS E BAGAGEM... Diário da Tarde. Belo Horizonte, 20 de abril de 1953, p. 6; Vermelho recrutará elementos da várzea. Diário da Tarde. Belo Horizonte, 29 de janeiro de 1955, p. 9; Cf. O CRUZEIRO REMOÇA O SEU ELENCO. Diário da Tarde. Belo Horizonte, 26 de maio de 1955, p. 8.

Cf. O AMADORISMO E SUAS COISAS. Diário da Tarde. Belo Horizonte, $1^{\circ}$ de fevereiro de 1957, p. 8.

35 Cf. "Blitzkrieg" contra o futebol mineiro. Diário da Tarde. Belo Horizonte, 7 de março de 1952, p. 6.

36 Cf. O ATLÉTICO DISPUTARÁ NA VARZEA. Diário da Tarde. Belo Horizonte, 22 de fevereiro de 1949 , p. 5.

37 Cf. O Atlético na várzea. Diário da Tarde. Belo Horizonte, 25 de fevereiro de 1949, p. 4.

38 Cf. O ATLÉTICO NA VARZEA. Diário da Tarde. Belo Horizonte. 15 de março de 1949, p. 5. 


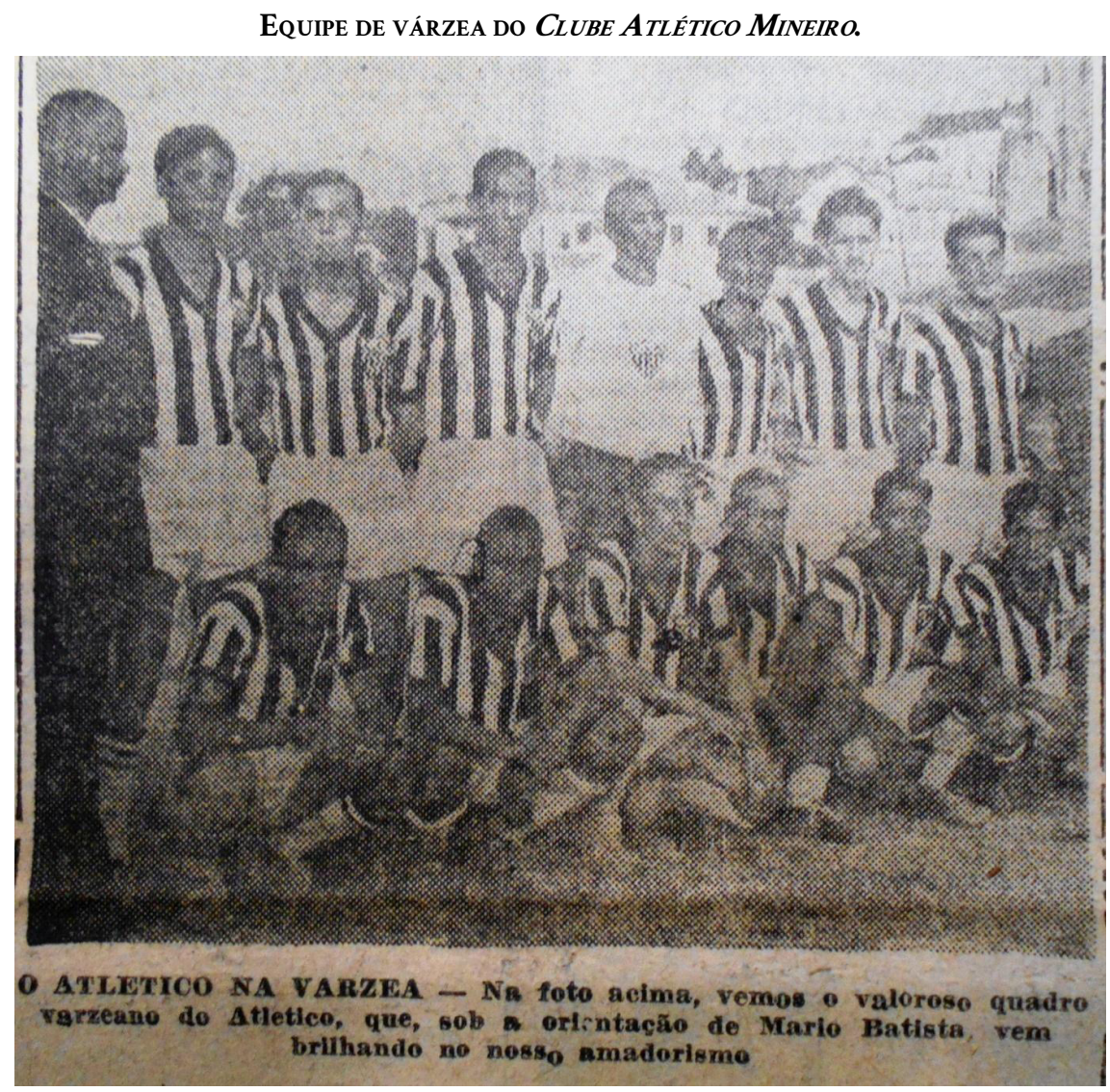

Fonte: Diário da Tarde. Belo Horizonte, p. 5, 3 de maio de 1949.

Com os jogadores vestidos com uniformes semelhantes aos da equipe principal do clube, ladeados por seu diretor técnico, "Matista", que aparece no canto esquerdo da imagem, de perfil, usando um terno, a composição da foto se distingue dos demais registros dos "onze" profissionais pela paisagem. Ao fundo não se ergue a estrutura de um estádio, se não que um cenário urbano, vista tão comum de espaços de jogo provisórios apropriados pelas agremiações de bairro em seu esforço de manter suas atividades e conduzir suas disputas.

A aventura varzeana do Atlético não prosperou como se esperava. A filiação ao DFA nunca se efetivou. Notícias esparsas davam conta de disputas pontuais pela cidade. Em 1952, ressurgiu o projeto, com a condução da seleção de atletas pelo então técnico do time principal, Yustrich ${ }^{39}$. O América teria sinalizado intenção semelhante, com a criação de um departamento amadorista $^{40}$. Depois de aparições ocasionais ${ }^{41}$, a passagem do Atlético pela várzea chegou ao fim em 1953, com alegações de despesas ao clube sem atendimento das finalidades ${ }^{42}$.

De toda maneira, tal experiência evidencia permeabilidades entre os circuitos de várzea e do futebol de espetáculo pouco concebíveis nos dias atuais, proporcionadas por um contexto 39 O ATLETICO VAI COMPETIR NO SETOR VARZEANO. Diário da Tarde. Belo Horizonte, p. 6, 8 de abril de 1952.

40 NOTAS AMADORISTAS. Diário da Tarde. Belo Horizonte, p. 5, 17 de outubro de 1952.

41 PAU DE ARARA. Diário da Tarde. Belo Horizonte, p. 6, 28 de novembro de 1952.

42 Notas da varzea. Diário da Tarde. Belo Horizonte, p. 7 e 11, 2 de junho de 1953. 
de incipiente profissionalismo ${ }^{43}$. Nesse período, não era raro que muitas equipes da divisão principal da FMF mantivessem amadores em seus times titulares. Em 1955, um caso inusitado chegou ao Tribunal de Justiça Desportiva local:

Com o recurso do America, pleiteando o ponto perdido no prélio contra o Asas, sob a alegação de que o clube de Lagoa Santa incluiu em sua equipe seis amadores, poderá agitar o futebol mineiro e transformar-se como ocorreu no caso Atlético x Vila, em uma longa e demorada "batalha judicial". (...)

O Asas na ultima sabatina incluiu em sua equipe os jogadores: Pireco, Teles, Helio, Gilberto e Ferreira registrados na Federação Mineira de Futebol como amadores. Também Saquarema que já requereu sua reversão ao amadorismo, mas não teve o seu processo despachado, participou da luta.

O recurso do América baseia-se no fato de que, sendo o certame de profissionais, não poderia o Asas disputar uma partida oficial com a maioria de seus jogadores pertencentes á classe inferior. (...)

Em 1948, quando era presidente da entidade o sr. Mario Gomes, a entidade mineira dirigiu-se à CBD consultando sobre a inclusão de amadores em quadros que participem de certames profissionais. A "eclética" respondeu que era permitida a participação de amadores, cabendo as federações regionais, fixar o numero de quantos poderiam jogar. Encaminhando o assunto ao Conselho Divisional, ficou assentado que poderiam intervir seis elementos amadores em cada equipe. (DIÁRIO DO TARDE, 1955, p. 9).

Vale lembrar que para fins de inscrição junto à FMF, o atleta precisava definir a sua condição, se amadora ou profissional, sendo possível a alteração a qualquer tempo, processo denominado reversão ${ }^{44}$. Como apontou a série de reportagens "Radiografia do profissionalismo mineiro" - citada no início deste artigo - boa parte das equipes era composta por jogadores que se desdobravam entre a prática esportiva e uma segunda colocação, não sendo interessante para muitos manterem vínculo empregatício com uma agremiação que não fosse a fonte principal de seu sustento.

A situação dos clubes profissionais era limitada em meados dos anos 1950. Com baixas rendas, não conseguiam manter seus quadros de atletas. Segundo diagnosticou o presidente do Cruzeiro, Eduardo Bambirra, em 1956, em entrevista ao Diário da Tarde:

A solução para Minas, onde existe um "semi-profissionalismo", com ordenados baixos (os clubes não podendo exigir muito dos atletas) e com rendas baixas (os clubes não podendo pagar muito aos atletas), seria a existência de um ambiente de melhor compreensão e entendimento entre os dirigentes e atletas, no sentido de proporcionar bons espetáculos ao publico. É necessário ainda que cada clube tenha outras fontes de renda, porque quando o quadro falhar, existe o dinheiro para se conseguir a melhora necessária. O Cruzeiro resolverá seu problema com a construção da séde social, que será uma fonte de renda segura a amparar o futebol nas horas difíceis. (DIÁRIO DA TARDE, 1956, p. 13)

Nesse contexto, a participação em uma equipe da primeira divisão da FMF não significava uma segurança empregatícia para o atleta ou uma perspectiva de progressão na carreira. Ao que parecia, suas escolhas levavam em conta, em muitos casos, ganhos de curto prazo ou perspectivas de atuação em outros ramos onde tivessem mais estabilidade. Dessa

43 Talvez, o recente processo de profissionalização do futebol de mulheres permita algumas aproximações com o contexto desse período.

44 Ainda hoje, existe a figura da reversão de atletas. No atual circuito de várzea de Belo Horizonte é muito comum a presença de atletas que, durante o primeiro semestre, atuam em competições amadoras, especialmente o campeonato do DFA e que, no segundo semestre, fazem a reversão ao profissional para atuarem no módulo II do campeonato mineiro, que corresponde à $3^{\text {a }}$ divisão da FMF. 
forma, as agremiações com mais visibilidade no circuito do futebol de espetáculo não tinham, necessariamente, uma vantagem concorrencial na contratação de jogadores.

Caso exemplar foi o dos atletas Ramos e Xavier que atuavam, respectivamente, por Atlético e Metalusina e que se transferiam, em 1950, para o Fluminense, equipe varzeana. A reportagem do Diário da Tarde questionava a escolha dos dois futebolistas que sabidamente retiravam seus proventos do esporte e preferiram se afiliarem a um clube do regime amador ${ }^{45}$. Outro episódio de repercussão foi o do atleta Amorim, originário da várzea, que, em 1951, havia assinado contrato com o Sete de Setembro, integrante da divisão principal da FMF e que recuou de sua decisão, para seguir no elenco do Pitangui, agremiação integrante do DFA, alegando que era mais bem pago atuando pela associação do bairro da Lagoinha ${ }^{46}$.

A oferta de vantagens financeiras pelos clubes de várzea era um tema relativamente recorrente nas páginas do Diário da Tarde. Falava-se abertamente sobre a atribuição de salários a treinadores, a exemplo dos contratos firmados entre Hemetério Chaves e o clube do Renascença ${ }^{47}$, do bairro homônimo ${ }^{48}$. Pagamentos em dinheiro por vitórias, popularmente conhecidos como "bichos", também eram citados em notas do periódico ${ }^{49}$.

Em alguns momentos, o jornal aprofundava o debate do tema, com acusações contra o falso amadorismo ou "marronismo", inclusive em outras modalidades ${ }^{50}$. Tais inferências poderiam se originar de entrevistas com integrantes de agremiações que se sentiam prejudicados pela prática ${ }^{51}$ ou da apuração dos próprios repórteres. Segundo coluna do Diário da Tarde:

\footnotetext{
Os clubes amadoristas da capital atravessam uma fase angustiosa, tendente a agravar-se. É que a condição de futebol amador, na pura acepção da palavra, já não existe em Belo Horizonte. Campeia a deslealdade entre os clubes, cujos jogadores não se veem mais na obrigação de adquirir o seu próprio material esportivo. Ninguém mais está cioso de que precisa auxiliar seu clube a viver, a progredir. Cuida-se, agora, tão somente, de zelar pelos seus próprios interesses, deixando-se de ser um jogador de futebol "amador", para transformar-se em um misto de "amador-profissional", condicionando as suas atuações, nas pelejas esportivas, aos "cruzeirinhos" que receber como gratificação para a assinatura de uma inscrição. (...)

Mas como sanar esse mal? Problema difícil, mas que não pode ficar sem estudos. E esses estudos devem ser iniciados pelo próprio Departamento de Futebol Amador. Os clubes honestos saberão cooperar. Existem casos concretos e do próprio conhecimento da entidade e dos clubes. Por que razão, pois, nunca se tem conhecimento de uma atitude do DFA? Ha pouco tempo, houve uma transação entre dois clubes da Lagoinha: O DFA sabe, os clubes sabem, os jogadores são conhecidos. Porque, então, se cruzam os braços? (DIÁRIO DA TARDE, 1949, p. 5).
}

45 Cf. CAMPEIA O “MARRONISMO” NO FUTEBOL AMADOR. Diário da Tarde. Belo Horizonte, p. 5, 18 de agosto de 1950.

46 Cf. DISPOSTO A DEMITIR-SE. Diário da Tarde. Belo Horizonte, p. 4, 4 de maio de 1951.

47 Cf. NOTAS AMADORISTAS. Diário da Tarde. Belo Horizonte, p. 5, 7 de janeiro de 1949; NOTAS

AMADORISTAS. Diário da Tarde. Belo Horizonte, p. 5, 19 de janeiro de 1949.

48 O bairro Renascença tem estreita relação com a Companhia Renascença Industrial, indústria têxtil existente ali. Boa parte de sua população vinculava-se direta ou indiretamente à fábrica, incluindo o clube, mantido com apoio da empresa. Cf. ARREGUY; RIBEIRO. Regional Nordeste, 2008.

49 Cf. NOTAS AMADORISTAS. Diário da Tarde. Belo Horizonte, p. 5, 31 de dezembro de 1948; FOAD CARAM APRESENTA: O FUTEBOL AMADOR E SUAS COUSAS. Diário da Tarde. Belo Horizonte, p. 8, 27 de junho de 1956.

50 Cf. “MARRONISMO” NO ESPORTE DO PEDAL. Diário da Tarde. Belo Horizonte, p. 12, 22 de fevereiro de 1952.

51 Cf. EXISTE O “MARRONISMO” NOS CLUBES AMADORISTAS. Diário da Tarde. Belo Horizonte, p. 9, 17 de agosto de 1949. 
Com uma narrativa que faz lembrar os debates de quase vinte anos atrás, antes da regulação do profissionalismo, a reportagem apontava para a prática disseminada, especialmente entre as equipes filiadas ao DFA, da oferta de vantagens financeiras aos jogadores. Tal situação implicaria em uma intensa movimentação dos atletas de um clube ao outro em busca de novos "cruzeirinhos" como gratificação pela inscrição. O fluxo de desportistas entre agremiações amadoras ou vindos do interior do estado era noticiado regularmente ${ }^{52}$. As constantes mudanças faziam com que a imprensa qualificasse os jogadores como "aves de arribação" 53 ou "aves sem ninho", insinuações de que eles se orientavam pelos benefícios que poderiam desfrutar em um novo local ${ }^{54}$.

Para controlar as transferências, o DFA propôs a criação de um período de estágio quando da mudança de um jogador de uma equipe a outra, que poderia se estender de 6 a 12 meses $^{55}$. A decisão esbarraria no fato de a entidade diretiva não ter submetido a deliberação ao conselho divisional, sendo mantida a liberdade na movimentação de atletas ${ }^{56}$.

A organização de uma seleção comerciária na cidade, formada por jogadores que atuavam em times de empresas do ramo, revelava como muitos atletas, vários deles inscritos por times filiados à FMF, buscavam a segurança de um emprego em outro setor, dadas as agruras do futebol de espetáculo daqueles tempos. Dentre os 17 convocados, 8 pertenciam a América, Atlético e Cruzeiro, sendo os outros 9 ligados a agremiações varzeanas ${ }^{57}$. Um quadro similar se observava no time da imobiliária COMITECO que, em 1955, era povoado de figuras ligadas ou com passagem pelo profissionalismo mineiro ${ }^{58}$.

Como demonstrou a série "Radiografia do profissionalismo mineiro", muitos dos integrantes da divisão principal da FMF se mantinham graças à articulação com algum ramo produtivo ou alguma empresa. Tal situação seria vista, mais uma vez, no caso de uma equipe varzeana, ligada do DFA, que se tornaria a primeira equipe amadora da cidade a se profissionalizar desde 1934, ano em que o Sete de Setembro aderiu ao regime.

Passados os debates sobre a possibilidade de Terrestre e Tremedal aderirem à divisão profissional da FMF, uma agremiação fabril de BH manifestou seu desejo de converter-se ao regime de remuneração de atletas. Era o Esporte Clube Renascença, entidade vinculada à Companhia Renascença Industrial que, a partir de 1951, iniciou movimentação para sua migração, com expectativas de compor o campeonato de elite do futebol local no ano de 1952. A seu favor, contava o apoio da fábrica e posse de um estádio próprio, com capacidade de receber público, no qual, inclusive, já realizava partidas com cobrança de ingressos ${ }^{59}$. Para

52 Cf. Ás vésperas do jogo como Flavio dos Santos, tomou-lhe os melhores elementos. Diário da Tarde. Belo

Horizonte, p. 5, 27 de agosto de 1949; APANHADO EM FLAGRANTE. Diário da Tarde. Belo Horizonte, p. 5, 14 de outubro de 1949; Mais uma do "player" Rodolfo. Diário da Tarde. Belo Horizonte, p. 5, 10 de agosto de 1950.

53 Essa mesma expressão foi identificada por Rodrigo Carrapatoso de Lima, para o futebol pernambucano dos anos 1910. Cf. LIMA, 2015, p. 217-231.

54 Cf. REORGANIZAÇÃO DO JUVENIL DO SETE. Diário da Tarde. Belo Horizonte, p. 5, 24 de outubro de 1951; Verdadeiras "aves sem ninho". Diário da Tarde. Belo Horizonte, p. 6, 2 de abril de 1952.

55 Cf. SEIS MESES DE ESTAGIO. Diário da Tarde. Belo Horizonte, p. 5, 11 de maio de 1950; ESTAGIO DE ATLETAS. Diário da Tarde. Belo Horizonte, p. 4, 23 de maio de 1950.

56 Cf. "QUEM NÃO TEM CÃO, CAÇA COM GATO”. Diário da Tarde. Belo Horizonte, p. 9, 31 de maio de 1950. 57 Cf. VARIOS PROFISSIONAIS NA SELEÇÃO COMERCIARIA. Diário da Tarde. Belo Horizonte, p. 3, 24 de outubro de 1952.

58 Cf. UM CLUBE, UM ESPORTE. Diário da Tarde. Belo Horizonte, p. 11, 4 de abril de 1955.

59 Cf. RENASCENÇA X INCONFIDENCIA. Diário da Tarde. Belo Horizonte, 25 de outubro de 1951, p. 5, 
tanto, já havia providenciado melhorias em suas instalações e sua retirada do $\mathrm{DFA}^{60}$.

Contra a pretensão do Renascença pesava a preocupação com um inchaço do campeonato profissional da FMF, considerando-se que o ingresso recente de novas equipes não havia se revertido em aumento das rendas ou da qualidade dos espetáculos ${ }^{61}$. A saída temporária encontrada pelo clube para se introduzir nas fileiras da FMF, uma vez que já se afastara do DFA, foi ingressar na competição de aspirantes da entidade estadual, reservada para atletas de até 21 anos de idade, junto com outra agremiação amadorista, o Necaxa. Tal decisão movimentou a elite de associações varzeanas, que passaram a pleitear o mesmo direito, sem sucesso ao fim do processo ${ }^{62}$.

Novas tentativas de preencher vagas de clubes desistentes do campeonato da primeira divisão aconteceriam nos anos seguintes ${ }^{63}$, mas seria apenas em 1958 que a agremiação fabril finalmente ascenderia ao profissionalismo, já com a fama de ter sido bicampeã de aspirantes dos anos de 1954 e $1955^{64}$. Para tentar custear o novo regime, a entidade desenvolvera um plano de negócios que conforme noticiado, consistia em:

\footnotetext{
O Renascença não deseja viver ás expensas da Fábrica de Tecidos. Foi elaborado um plano de independência. O clube passou a explorar a loja de vendas a varejo localizada junto ao estádio e, agora, já se prepara para inaugurar mais duas lojas: uma no Horto e outra nas proximidades do Mercado. Adquirindo a mercadoria na Fábrica, a preço especial, o Renascença espera conseguir, nas vendas a varejo, o necessário para cobrir as despesas com o plantel, ao mesmo tempo que oferecerá, nas lojas, emprego aos seus profissionais (DIÁRIO DA TARDE, 1958, p. 5).
}

Com um elenco que, a exemplo da maioria das equipes da divisão principal da FMF, mesclava amadores e profissionais ${ }^{65}$, o Renascença tentava encontrar uma alternativa de renda e de ocupação para seus atletas, pois como indicara o presidente do Cruzeiro, citado anteriormente, havia a necessidade de criação de novas saídas pelas agremiações, dada a escassez das verbas proporcionadas pelas bilheterias. A aventura desse time que fez a transição do circuito de várzea para o do futebol de espetáculo duraria até o ano de 1966, quando disputou pela última vez o campeonato mineiro de profissionais e terminou a competição na última posição.

Em 1968, era traçado um plano para o retorno da equipe à divisão principal. A passagem pelo profissionalismo havia deixado o clube em difícil crise financeira, com pressões da fábrica, que retirara o apoio ao projeto. A nova presidência que assumira, tentava sanar dívidas e projetava novas formas de arrecadação com torneios esportivos e bailes carnavalescos nas 60 Cf. O RENASCENÇA QUER INGRESSAR NO FUTEBOL PROFISSIONAL. Diário da Tarde. Belo Horizonte, 9 de novembro de 1951, p. 4.

61 Cf. ASAS E PAISSANDÚ INCLUIDOS NA DIVISÃO DE PROFISSIONAIS. Diário de Tarde. Belo Horizonte, 10 de junho de 1952, p. 4.

62 Cf. Vários clubes do DFA querem disputar o certame de aspirantes. Diário da Tarde. Belo Horizonte, 10 de junho de 1952, p. 5; E O CAMPEONATO DE AMADORES? Diário da Tarde. Belo Horizonte, 3 de junho de 1953, p. 8. 63 Cf. RENASCENÇA E BELA VISTA (SETE LAGOAS), OS CANDIDATOS À VAGA DO METALUSINA. Diário da Tarde. Belo Horizonte, 24 de fevereiro de 1954, p. 9; Esta noite o Renascença decidirá seu ingresso ou não no profissionalismo. Diário da Tarde. Belo Horizonte, 27 de dezembro de 1954, p. 9.

64 Cf. RENASCENÇA - O PRIMEIRO TIME DE B. HORIZONTE A PROFISSIONALIZAR-SE. Diário da Tarde, Belo Horizonte, $2^{\circ}$ caderno, 10 de maio de 1958 , p. 6.

65 Cf. RENASCENÇA - O PRIMEIRO TIME DE B. HORIZONTE A PROFISSIONALIZAR-SE. Diário da Tarde, Belo Horizonte, 10 de maio de 1958, p. 6. 
dependências da agremiação ${ }^{66}$. O Renascença nunca voltaria ao profissionalismo, mas seguiria por décadas atuando no circuito varzeano local.

\section{CONSIDERAÇõES FINAIS}

Clubes como o Tremedal, o Terrestre, o Pitangui e o Fluminense, dentre outros similares, constituíam a elite do meio amadorista local. Agremiações do tipo integraram o segundo escalão dos torneios de futebol de espetáculo antes da oficialização da remuneração de atletas, em 1933, e se transferiram para o circuito de várzea desde então. Em alguns casos, poderiam rivalizar com as equipes profissionais na contratação de um jogador, mesmo que não arrecadassem com a realização de suas partidas. Seu funcionamento estava baseado em lógicas de não mercantilização do jogo, com mecanismos tradicionais de financiamento, por meio de doações de patronos locais, além de arrecadações de seu corpo de sócios e de eventuais recursos públicos.

Essa elite varzeana não se baseava apenas em tradição. Seus integrantes se renovavam, ainda que a lógica de sua constituição seguisse a mesma fórmula. Um exemplo dessa atualização foi a criação do Rosário, equipe capitaneada e patrocinada pelo empresário do ramo de restaurantes Rosário Scotelaro, com longa trajetória no amadorismo local ${ }^{67}$, e que replicava o sistema de arregimentação de atletas que viviam na fronteira entre o amadorismo e o profissionalismo ${ }^{68}$. Caberia a ela o protagonismo do circuito da várzea nos anos 1960, quando conquistaria títulos do DFA em sequência e se tornaria o conjunto mais prestigiado da cidade.

Lançadas ao amadorismo, menos por sua vontade e mais pelas contingências impostas, a partir de 1933, pela regulamentação do regime de pagamento de salários aos jogadores, tais agremiações não renegavam a oferta de benefícios financeiros aos seus atletas. Contudo, sem a posse de estádios fechados que possibilitassem a cobrança de ingressos para as partidas, não viam condições para a migração para o circuito do futebol de espetáculo que, no final da década de 1940, restringia-se a menos de uma dezena de clubes da parte central de Minas Gerais.

$\mathrm{Na}$ outra ponta, os clubes tradicionais da cidade que desde a constituição das primeiras ligas foram capazes de hegemonizar o processo de organização do meio esportivo local, enfrentavam dificuldades para fomentar um mercado capaz de gerar renda suficiente para sustentar o profissionalismo. A escassez de público nos jogos, a baixa lucratividade das principais partidas, dada a pouca capacidade dos estádios, e a falta de embates de interesse ao longo do ano eram alguns dos motivos para a incipiência do espetáculo esportivo naqueles tempos.

Seria apenas nos anos 1960 que se observaria uma maior consolidação do circuito do futebol de espetáculo na capital mineira, impulsionada pela construção do estádio do Mineirão, por uma progressiva integração nacional das competições e pelo sucesso esportivo, em especial de Cruzeiro e Atlético. Ao se observar a lenta constituição de um circuito de várzea em BH, em especial, a partir da atuação dos clubes da elite desse universo, percebe-se que as

66 Cf. MELANE, Antônio Carlos. Minas ganha de nôvo o futebol do Renascença. Diário da Tarde. Belo Horizonte, p. 13, 15 de fevereiro de 1968.

67 Cf. NOVA FASE PARA O ITAUNENSE. Diário da Tarde. Belo Horizonte, p. 5, $1^{\circ}$ de fevereiro de 1949.

68 Cf. LIMA, Veiga. COLUNA DA VÁRZEA. Diário da Tarde. Belo Horizonte, p. 2, $2^{\circ}$ caderno, 22 de outubro de 1964; LIMA, Veiga. COLUNA DA VÁRZEA. Diário da Tarde. Belo Horizonte, p. 9, 6 de novembro de 1964. 
tensões entre profissionalismo e amadorismo, assim como começaram sua história muito antes de 1933, da mesma forma não foram terminadas naquele momento. O processo de configuração do espetáculo futebolístico se estendeu por todo o século $\mathrm{XX}$, sendo que essa oposição entre os regimes de remuneração foi ressignificada, ao longo das décadas, em diálogo com o fenômeno de mais larga escala. 


\section{REFERÊNCIAS BIBLIOGRÁFICAS}

ARREGUY, Cintia Aparecida Chagas; RIBEIRO, Raphael Rajão (coord.). Histórias de bairros [de] Belo Horizonte: Regional Nordeste. Belo Horizonte: Arquivo Público da Cidade, 2008.

BOURDIEU, Pierre. Como é possível ser esportivo? In: Questões de sociologia. Rio de Janeiro: Ed. Marco Zero Limitada, 1983, p. 136-153.

BRASIL. Decreto-Lei 3.199/41. In: Câmara dos Deputados. Disponível em: https://www2.camara. leg.br/legin/fed/declei/1940-1949/decreto-lei-3199-14-abril-1941-413238-publicacaooriginal-1pe.html. Acesso em: 29 ago. 2021.

DAMO, Arlei Sander. Do dom à profissão: uma etnografia do futebol espetáculo a partir da formação de jogadores no Brasil e na França. Tese (Doutorado em Antropologia Social) Universidade Federal do Rio Grande do Sul, Porto Alegre, 2005.

DAMO, Arlei. Futebóis - da horizontalidade epistemológica à diversidade política. FuLiA/ UFMG, Belo Horizonte, v. 3, n. 3, p. 37-66, set.-dez. 2018.

DIÁRIO DA TARDE. A influência do Tremedal no amadorismo de B. Horizonte. Belo Horizonte, p. 8 e 9, 5 de janeiro de 1956.

DIÁRIO DA TARDE. O sete não pode amarrar-se mais à mentalidade amadorista. Belo Horizonte, p. 6, 20 caderno, 17 de julho de 1958.

DIÁRIO DA TARDE. Radiografia do profissionalismo mineiro. Belo Horizonte, p. 8, 4 de julho de 1956.

DIÁRIO DA TARDE. Terrestre e Tremedal. Belo Horizonte, p. 5, 2a edição, 13 de dezembro de 1948.

GAMBETA, Wilson Roberto. A bola rolou: O Velódromo Paulista e os espetáculos de futebol (1895-1916). Tese (Doutorado em História) - Faculdade de Filosofia, Letras e Ciências Sociais, Universidade de São Paulo, São Paulo, 2013.

GOMES, Eduardo de Souza; PINHEIRO, Caio Lucas Morais (org.). Olhares para a

Profissionalização do Futebol: Análises Plurais. Rio de Janeiro: Multifoco, 2015.

MAGNANI, José Guilherme C. Quando o Campo é a Cidade: Fazendo Antropologia na Metrópole. In: MAGNANI, José Guilherme C; TORRES, Lilian de Lucca (org.). Na Metrópole: textos de antropologia urbana. São Paulo: Editora da Universidade de São Paulo; Fapesp, 2008, p. $12-53$.

MASCARENHAS, Gilmar. Entradas e bandeiras: a conquista do Brasil pelo futebol. Rio de Janeiro, EdUERJ, 2014.

MAYOR, Sarah Teixeira Soutto. O futebol na cidade de Belo Horizonte: amadorismo e profissionalismo nas décadas de 1930 e 1940. Tese (Doutorado em Estudos do Lazer) Universidade Federal de Minas Gerais, Belo Horizonte, 2017.

LAGE, Marcus Vinicius Costa; MEDEIROS, Regina de Paula. Aspectos sociológicos da profissionalização do futebol em Belo Horizonte nas décadas de 1920 e 1930. Esporte e Sociedade, Niterói, ano 9, n. 23, p. 1-14, mar. 2014.

LIMA, Rodrigo Carrapatoso de. Aves de arribação - o processo de “importação" de jogadores na cidade do Recife: conquistando glórias a preço de ouro (1915-1920). In: GOMES; PINHEIRO, 2015, p. 217-231. 
LINHALES, Meily Assbú. A trajetória política do esporte no Brasil: interesses envolvidos, setores excluídos. 1996. Dissertação (Mestrado em Ciência Política) - Faculdade de Filosofia e Ciências Humanas, Universidade Federal de Minas Gerais, Belo Horizonte, 1996.

MYSKIW, Mauro. Nas controvérsias da várzea: trajetórias e retratos etnográficos em um circuito de futebol da cidade de Porto Alegre. Tese (Doutorado em Ciências do Movimento Humano) - Universidade Federal do Rio Grande do Sul, Porto Alegre, 2012.

PEREIRA, Leonardo Affonso de Miranda. Footballmania: Uma história social do futebol no Rio de Janeiro, 1902-1938. Rio de Janeiro: Nova Fronteira, 2000.

RIBEIRO, Raphael Rajão. A bola, as ruas alinhadas e a uma poeira infernal: os primeiros anos do futebol em Belo Horizonte (1904-1921). Rio de Janeiro: Drible de Letra/Multifoco, 2018.

SANTOS JUNIOR, Nei Jorge dos. A construção do sentimento local: o futebol nos arrabaldes de Bangu e Andaraí. Rio de Janeiro, Multifoco, 2014.

SANTOS, João Manuel Casquinha Malaia. Revolução Vascaína: a profissionalização do futebol e a inserção sócio-econômica de negros e portugueses na cidade do Rio de Janeiro (1915-1934). Tese (Doutorado em História Econômica) - Faculdade de Filosofia, Letras e Ciências Sociais, Universidade de São Paulo, São Paulo, 2010.

SOUZA, Denaldo Alchorne de. O Brasil em ação! Construções e reconstruções da identidade nacional (1930-1947). São Paulo: Annablume, 2008.

SOUZA, Glauco José Costa. “Adiantam-se bastante nos subúrbios”: o desenvolvimento do futebol na região suburbana do Rio de Janeiro (1907-1924). Dissertação (Mestrado em História) Universidade Federal Fluminense, Niterói, 2018.

SOUZA, Jhonatan Uewerton; CAPRARO, André Mendes. "Mercadorias postas em leilão": tensões sociais no prematuro processo de reconhecimento do profissionalismo no futebol paranaense. In: GOMES; PINHEIRO, 2015, p. 235-263.

SOARES, Jorge Miguel Acosta. Justiça desportiva: o Estado Novo entra em campo (1941-1945). 2015. Tese (Doutorado em História Social) - Pontifícia Universidade Católica de São Paulo, São Paulo, 2015.

WITTER, José Sebastião; MEIHY, José Carlos Sebe Bom e. Futebol...Futebol. In:

Futebol e cultura: coletânea de estudos. São Paulo: Imprensa Oficial/Arquivo do Estado, 1982, p. 71-86. 